\title{
A distração da meninada nas ruas de São Paulo no início do século XX
}

\author{
How kids enjoyed themselves on the streets of São Paulo in the beginning of the 20th
}

century

Eliane Mimesse Prado

\section{RESUMO}

As crianças e jovens que viviam na cidade paulistana nos anos iniciais do século XX tiveram seus momentos para a diversão, normalmente com grupos de amigos. Identificaram-se brincadeiras e jogos conhecidos entre esses sujeitos. A cidade de São Paulo crescia a cada dia, com a entrada de imigrantes das mais diversas etnias. As novas fábricas atraiam a mão de obra que estava ociosa no interior do estado. O aumento no fluxo de bondes para o transporte de passageiros e de carroças de serviços nas ruas cresceu, na mesma proporção que as fábricas. As ruas tornaram-se mais movimentadas e, consequentemente, mais perigosas, começaram a ameaçar e restringir a diversão da meninada. A fonte primária para este estudo foram as notícias de um periódico em circulação chamado $O$ Estado de S. Paulo. As referências teóricas foram compostas por Cruz (2013) quando tratou da urbanização da cidade paulistana e de Pereira (2010) que focou no desenvolvimento fabril e urbano no início do século XX; Moura (2000) abordou a questão do trabalho infantil na urbe; e Autor (2018) por estudar os abandonados e órfãos na capital paulista; entre outros. Conclui-se que, apesar da expansão da cidade e do breve trânsito nas ruas, as crianças e jovens conseguiram divertir-se e encontrarem locais para sua recreação.

Palavras-chave: Brincadeiras de rua. História da infância. História da educação.

\begin{abstract}
Children and young adults who lived in the city of São Paulo in the early $20^{\text {th }}$ century found some time for enjoyment, usually among friends. We have identified the play activities and games that were familiar to them. The city of São Paulo was growing day by day due to the arrival of immigrants from varied ethnic backgrounds. New factories attracted the unemployed from the state's countryside. Streetcars with passengers were coming and going more often and the number of service carriages going along the streets increased to the same extent as the factories. Streets became busier and, as a consequence, more dangerous, jeopardizing and hampering the children's play activities. This study's main source were the news stories from a local newspaper, $O$ Estado de $S$. Paulo. The theoretical framework emcompassed authors such as Cruz (2013), who addresses São Paulo's urbanization, and Pereira (2010), who focuses on the urban and

1 Universidade Estadual de Maringá (UEM), PR, Brasil. Doutora em Educação, e-mail: mimesse.e@gmail.com http://orcid.org/0000-0001-5084-2255

Rev. Caminhos da Educação: diálogos, culturas e diversidades, Teresina, v. 2, n. 1, p. $127-12742$ jan./abr. 2020
\end{abstract}


industrial growth in the early $20^{\text {th }}$ century; Moura (2000), since he addresses child labor in the city; and Autor (2018), for her studies about abandoned and orphaned children in the city of São Paulo; among others. We have reached the conclusion that even though the city was growing and there was a little traffic on the streets, children and young adults were able to enjoy themselves and find recreation areas.

Keywords: Street play. History of childhood. History of education.

\section{Resumen}

Los niños y jóvenes que vivían en la ciudad de São Paulo a principios del siglo XX tuvieron momentos para diversión, normalmente con grupos de amigos. Se identificaron los juegos conocidos entre esos sujetos. São Paulo crecía cada día, con el ingreso de inmigrantes de las más diversas etnias. Las nuevas fábricas atraían la mano de obra que estaba ociosa en el interior del estado. El incremento en el flujo de tranvías para el transporte de pasajeros y de carrozas por las calles creció en la misma proporción que las fábricas. Las calles se volvieron más transitadas $\mathrm{y}$, consecuentemente, más peligrosas, empezaron a amenazar y restringir la diversión de los niños. La fuente primaria para esta investigación fueron las noticias de un periódico en circulación por la ciudad, $O$ Estado de S. Paulo. Las referencias teóricas se componen de Cruz (2013) cuando trata de la urbanización de la ciudad de São Paulo - y de Pereira (2010) - que enfocó el desarrollo fabril y urbano a comienzos del siglo XX; Moura (2000) por abordar la cuestión del trabajo infantil en la urbe; y Autor (2018), cuando estudió los abandonados y huérfanos en esta capital; entre otros. Se concluye que, a pesar de la expansión de la ciudad y del breve tráfico en las calles, los niños y jóvenes consiguieron divertirse y buscar sitios para su recreación.

Palabras-clave: Juegos de calle. Historia de la infancia. Historia de la educación.

\section{Vasculhando as fontes, resgatando os indícios}

Para agregar as informações acerca dos jogos e brincadeiras das crianças e jovens em alguns dos bairros centrais da cidade paulistana, foram necessárias muitas horas de pesquisas e leituras de notícias em variados periódicos da época. Os indícios, para o início deste estudo, foram detectados em pesquisa anterior, efetuada em um núcleo colonial com predomínio de famílias de colonos provindos da região do Vêneto, na Itália. Esse referido estudo focou a singularidade da escolarização elementar das crianças nas terras brasileiras, que viviam em uma comunidade com uma identidade nacional e linguística muito forte e que estavam muito próximos geograficamente da cidade de São Paulo, como citado pelo Autor (2010). Foi perceptível nesta pesquisa identificar como as crianças usavam o espaço público, tornando-o privado, as brincadeiras expandiam-se e, quando existia companhia, os locais se alargavam e misturavam-se, como foi descrito no texto pelo Autor (2013). No depoimento oral 
desses sujeitos discorrendo sobre sua infância, muitas décadas depois, eles referiram-se ao trabalho executado como algo que era suavizado pelas brincadeiras. Deste pequeno grupo de bambini ${ }^{2}$ que a pesquisa se expande para a cidade de São Paulo.

Após vários meses de leituras e análises, foi selecionado um periódico para este estudo, por apresentar grande número de notícias sobre os meninos e um discurso específico com relação à esta população. A fonte, neste caso, foi essencial para estabelecer o objeto da pesquisa. A partir da leitura das entrelinhas das notícias, porque efetivamente, nenhuma notícia referiu-se ao jogo dos jovens nas ruas ou a brincadeira das crianças em determinados locais. A pesquisa demandou tempo por ser necessária a leitura de várias notícias diárias sobre a cidade, para em seguida extraírem-se as informações para compor o objeto do estudo. Então, como referido por Certeau (2011, p.82) "[...] o estabelecimento das fontes solicita, também, hoje, um gesto fundador, representado, como ontem, pela contribuição de um lugar, de um aparelho ou de técnicas". Cada tipo de fonte necessita de uma técnica diferente, neste caso, foi a leitura das notícias nas páginas do periódico nos anos estabelecidos, o início do século XX. Foi necessária a leitura com outro olhar, buscando os indícios nos fragmentos dos comentários descritos nas matérias.

O periódico escolhido foi eleito por trazer, em seu todo, um maior conjunto de notícias a respeito do assunto. Na cidade paulistana existiram muitos periódicos que circulavam diariamente em língua portuguesa e nos idiomas dos muitos imigrantes que viviam na cidade. Um bom exemplo é o periódico Avanti! giornale socialista quotidiano, com tiragem de 3 mil volumes em língua italiana, no ano de 1908 e, este era apenas um dos jornais com ampla circulação na cidade. Também existiam os anarquistas, os moderados em língua italiana e em língua portuguesa eram vários diários e semanários cômicos, literários, agrícolas, comerciais.

Foi indicado por Eleutério (2013) que a época da Primeira República conduziu às mudanças na imprensa, em decorrência das modernizações, ampliando suas tiragens e a qualidade da impressão, além de baixar o seu custo. Essas ações possibilitaram ao novo século portar o 'progresso' da imprensa brasileira como um de seus signos.

É bom lembrar ao leitor que a população imigrante era minimamente alfabetizada e, as escolas primárias de Primeiras Letras estavam repletas de alunos, supõe-se que o número de leitores de jornais fosse amplo. Se levarmos em conta os

\footnotetext{
${ }^{2}$ Crianças em língua italiana.

Rev. Caminhos da Educação: diálogos, culturas e diversidades, Teresina, v. 2, n. 1, p. 127-129 42 jan./abr. 2020
} 
dados de pesquisa do Autor (2015) existiam no ano de 1906, 4.332 mil alunos matriculados nas 129 escolas públicas isoladas, sendo 43 masculinas, 52 femininas e 34 mistas; e 7.111 alunos matriculados nos 17 Grupos Escolares. Então em 1906, contamos com um total de pouco mais de 11 mil alunos matriculados em escolas de Primeiras Letras na cidade de São Paulo. E, em 1908, existiam 5 mil alunos matriculados nas 77 escolas multiseriadas italianas subsidiadas privadas, que seguiam o mesmo modelo das escolas isoladas públicas. A população da cidade paulistana apresentava crescimento, conforme demonstrou Pereira (2010) no ano de 1900 existiam 240 mil habitantes e em 1914 atingiu o total de 477.992 habitantes. Por esses dados pode-se ter ideia de quantos leitores existiam na cidade, tanto em língua portuguesa quanto em língua italiana.

Os periódicos poderiam ser lidos por adultos alfabetizados e por qualquer destes alunos matriculados nas escolas elementares, que já fossem alfabetizados e conseguissem ler para seus familiares. Aliás, os meninos vendedores de jornais ambulantes, nem sempre eram alfabetizados. Muitos deles frequentavam as escolas noturnas, como foi escrito pelo Autor (2018), para aprenderem a ler. Porque muitos deles vendiam os jornais pelas notícias que traziam na primeira página, mas somente reproduziam o que ouviam, não sabiam o que estava escrito.

Porém, o periódico utilizado aqui como objeto de estudo, tendia a seguir uma linha que vislumbrava para a classe trabalhadora e, seus filhos por consequência, a disciplina, o patriotismo e o trabalho, em suma "a ordem e o progresso". As crianças e jovens, apesar de estarem nas ruas brincando, eram presas e punidas por seus atos. Suas brincadeiras nem sempre atingiam outras pessoas, muitas vezes elas próprias se machucavam. A partir do tumulto de uma brincadeira de rua, a polícia era chamada e as crianças e jovens eram presos, por "perturbarem a ordem".

Moradores das ruas Rego Freitas, Marquez de Itu e Santa Izabel pedem-nos que chamemos a atenção de quem competir por um grupo de insubordinados menores, que andam por ali fazendo constantes diabruras, sem que a isso os guardas da ronda liguem grande importância. (SÃO PAULO, 11/9/1906, p.3) 
O Estado de S. Paulo era um jornal diário, composto por uma média de quatro a cinco páginas, contendo muitos reclames na última página ${ }^{3}$. O recurso de publicar somente anúncios nas últimas páginas era algo que passou a ocorrer com mais frequência no século XX. Vários periódicos, não somente o que foi utilizado como objeto de estudo, utilizavam-se da publicidade para angariar mais fundos e expandir a impressão.

Normalmente, nas páginas iniciais foram encontradas as sessões 'Avulsos' ou 'Notícias diversas' e, nestes locais, estavam as informações sobre as crianças e jovens. De modo que, como foi descrito por Certeau (2011, p. 82) “[...] não há trabalho que não tenha de utilizar de outra maneira os recursos conhecidos. Não se trata apenas de fazer falar estes imensos setores adormecidos da documentação e dar voz a um silêncio. Significa transformar alguma coisa". A intenção do periódico era apenas a de narrar os fatos ocorridos. Tudo o que acontecia e que poderia ser descrito e publicado, sem ofender a moral do público leitor. Este periódico era um dos poucos, na época, que publicava todos os dias descrições detalhadas dos fatos cotidianos. Este jornal diário tinha um público leitor razoável, os números de suas tiragens contribuem para confirmar sua expansão: no ano de 1890 sua tiragem foi de 8 mil exemplares, em 1908 de 18 mil exemplares ${ }^{4}$. Luca $(2005$, p.138) comentou sobre essa situação que predominou na imprensa até os anos de 1950. Porque antes deste período "consagrava-se a ideia de que o jornal cumpria a função de informar ao leitor o que se passou, respeitando rigorosamente a "verdade dos fatos"”, exatamente o que ocorre com muitas notícias deste periódico, as narrativas eram detalhadas, continham até os nomes e endereços das pessoas citadas.

E, por fím a última questão a respeito da pesquisa com notícias de jornais no século XXI, e o suporte em que são apresentados atualmente. A busca digital predomina nas hemerotecas, que são em sua maioria virtuais. A cada dia será mais difícil termos contato com os jornais originais, mesmo usando luvas ou microfilmes. A digitalização

\footnotetext{
${ }^{3}$ A partir da segunda metade do século XIX com o telégrafo todos os jornais tenderam a crescer em volume de notícias, como foi descrito por Matheus (2014). Os periódicos maiores mantinham colunas dedicadas aos telegramas. Com a criação do cabo submarino que ligou o Brasil a Europa, as notícias chegavam com mais rapidez. Mas, apesar da modernidade em prática no século XX, anunciando a primeira guerra, por exemplo, ainda existiam as sessões 'Cartas', que publicavam notícias de algum país aonde o jornal contava com um repórter em campo de batalha.

${ }^{4} \mathrm{O}$ jornal continua em circulação, a tiragem de 2018 foi de 107,4 mil exemplares. Foi criado em 1875, por um grupo de cafeicultores ligados ao Partido Republicano Paulista (PRP), com o nome A Província de São Paulo, sua nomenclatura foi alterada após a Proclamação da República. Implantou a venda de espaços para publicação de reclames e anúncios no século $\mathrm{XX}$, além de vender exemplares avulsos. Rev. Caminhos da Educação: diálogos, culturas e diversidades, Teresina, v. 2, n. 1, p. 127-131 42 jan./abr. 2020
} 
esta tornando a materialidade um termo fluído, atualmente o visual é virtual, mas em contraponto o acesso aos acervos se expandiu. Chartier (2010, p. 9) descreveu esta situação quando abordou a questão da revolução digital e o necessário rompimento com nossas ações vinculadas à escrita, será preciso "quebrar o vínculo antigo estabelecido entre textos e objetos, entre discursos e sua materialidade, a revolução digital obriga a uma revisão radical dos gestos e das noções que associamos ao escrito". Portanto, a pesquisa desenvolveu-se com uma fonte impressa, utilizando-se de uma nova abordagem - agora - virtual e metodológica, por analisar de outra maneira as entrelinhas dentro do contexto que, a princípio, a compuseram.

\section{O crescimento urbano e a vida cotidiana}

Nos anos finais do século XIX, e durante os primeiros anos do século XX a cidade de São Paulo recebeu grande número de novos moradores. Em decorrência do necessário desembarque dos estrangeiros na Hospedaria dos Imigrantes que se localizava na cidade, como foi explicado por Autor (2018). De modo que, todo imigrante que chegava ao estado de São Paulo deveria desembarcar do navio no porto de Santos e subir a Serra do Mar rumo a Capital de trem até esta Hospedaria, para depois ser encaminhado para seu destino final. Mas, não só de imigrantes recémchegados contava a população da cidade, existiam os antigos moradores e os novos habitantes, vindos de outras localidades do próprio país. De acordo com a pesquisa de Cruz (2013), nos anos de transição, entre os séculos XIX e XX a população da cidade era formada por $55 \%$ de imigrantes, $11 \%$ de negros e de mulatos.

Os novos moradores da cidade também eram procedentes do interior do estado. Normalmente pequenos grupos de imigrantes, de uma mesma etnia, alocados nas fazendas de café no interior e, que não se adaptaram ao trabalho na lavoura. Essas pessoas mudavam-se em busca de trabalho nas novas fábricas.

A superprodução da safra paulista de café, que ocorreu entre os anos de 1906 e 1907 obrigou também, grande parte da mão de obra desempregada, do interior do estado a buscar trabalho nas fábricas da Capital. Pereira (2010) apresentou os dados entre os anos de 1900 e 1915, quando ocorreu a expansão do número de cotonifícios, moinhos de farinha de trigo, fábricas de chapéus, calçados, marcenarias e cerâmicas na cidade paulistana. Todas essas novas fábricas necessitavam de mão de obra. 
A questão que nos toca, quanto ao trabalho nas fábricas, é que todos poderiam trabalhar. Como citado por Moura (2000) as fábricas empregavam crianças de várias idades diferentes, existiam máquinas reduzidas para adaptarem-se ao trabalho dos pequenos. Matos (2002) pesquisou o trabalho das filhas de imigrantes portuguesas, meninas que a partir dos 7 ou 8 anos de idade poderiam ser contratadas para os trabalhos domésticos. Biondi (2010) descreveu que as crianças trabalhavam desde 7 ou 8 anos nas fábricas junto de seus pais. A questão crucial neste ponto é - se essas crianças trabalhavam nas fábricas, não poderiam frequentar as escolas primárias públicas ou privadas elementares subsidiadas pelo governo italiano. Contávamos, portanto, com um grande grupo de crianças e jovens trabalhadores e analfabetos, que só podiam sair para brincar nos dias que não trabalhavam.

$\mathrm{Na}$ área central da cidade predominavam escolas primárias públicas, principalmente com a criação de Grupos Escolares e as subsidiadas elementares italianas, como citou Autor (2015). As escolas subsidiadas pelo governo italiano eram elementares, seguiam um modelo muito similar ao das escolas isoladas paulistas. Apenas o governo italiano, subsidiava escolas elementares para seus emigrados que estivessem vivendo em outros países. As isoladas públicas e privadas subsidiadas eram multiseriadas, separadas por sexos, ensinavam os rudimentos da leitura, escrita e aritmética. As italianas contribuíam com a construção e fortalecimento da identidade e, do nacionalismo italiano ao emigrado recém-saído de um país a pouco tempo unificado e, ainda sem uma identidade nacional instituída.

As escolas públicas poderiam ser de modalidades diferentes, as Isoladas - de três tipos: femininas, masculinas ou mistas, com uma única sala de aula, compostas com alunos de idades e níveis de aprendizagens diferentes; Reunidas - era a junção de algumas escolas isoladas com salas únicas e multiseriadas no mesmo espaço físico, independentes entre si e, os Grupos Escolares - organizados de acordo com a idade e a aprendizagem, eram separados por sexo e divididos em anos de ensino.

A frequência nas aulas das escolas públicas primárias e das italianas elementares não era obrigatória e, essa situação gerava a possibilidade das crianças e jovens, que não trabalhavam nas fábricas conseguirem algum tipo de emprego que fosse sazonal. Esses mesmos sujeitos também teriam mais tempo para se divertir com seus companheiros pelas ruas. Sendo assim, as escolas primárias estavam repletas de alunos matriculados, mas a frequência era baixa. Autor (2010) analisou os relatórios dos professores enviados Rev. Caminhos da Educação: diálogos, culturas e diversidades, Teresina, v. 2, n. 1, p. 127-133 42 jan./abr. 2020 
para a Diretoria de Ensino e, verificou que existia um número mínimo de alunos matriculados para manter o salário do professor. A obrigatoriedade, não poderia ser instituída legalmente, porque não existia o número de vagas suficientes para todos os alunos em idade escolar.

Neste período o contingente de crianças e jovens eliminados das aulas era amplo, pelos mais diversos motivos, eram essas as crianças que estavam no trabalho ambulante e tinham tempo para jogar bola durante o dia ou estavam nas ruas em busca de alguma atividade como ajudante e, encontravam companhia para uma brincadeira. Claro, também tinham os jovens que viviam nas ruas, em pequenos grupos efetuando roubos. Segue abaixo um exemplo de jovens excluídos, em uma notícia sobre alguns "menores vadios" que foram presos por terem se entregado "a mais desenfreada gatunagem". Esses meninos não tinham residência fixa, dormiam nas ruas e efetuavam roubos.

Na delegacia de polícia de Santa Ephigenia ficou hontem o processo que o dr. Ascanio de Cerquera iniciou contra os menores Antonio Pereira, Manoel Gomes da Silva, Delphino José e Moysés de Azevedo, todos os quaes, ao abandono, sem domicilio certo, vadiando, se entregavam á mais desenfreada gatunagem, assaltando diariamente a propriedade alheia.

$\mathrm{O}$ processo foi instaurado para o fim de serem os menores referidos internos no Instituto Disciplinar. (SÃO PAULO, 06/01/1909, p. 3)

O espaço reduzido dentro da moradia também era um fator que levava as crianças e jovens a brincarem na rua. Tendo em conta, o baixo salário recebido por seus responsáveis os cortiços eram os locais mais acessíveis para sua estada na Capital. Esses tipos de imóveis populares foram construídos "nos bairros centrais, nas localidades mais próximas das baixadas e das áreas alagadiças. Os cortiços agruparam imigrantes de diferentes etnias, mas em alguns bairros foi possível a união de grupos de indivíduos procedentes de uma mesma região", como descreveu Autor (2018, p. 121).

A população de baixa renda concentrou-se na região próxima dos rios, nos fundos dos armazéns, que carregavam e descarregavam os trens, nas áreas entre os rios e as fábricas, nas áreas em que, quando chovia, eram alagadas. Os cortiços foram construídos em ruas desse entorno próximos das fábricas. As crianças e jovens viveram nesse mesmo ambiente, como foi descrito abaixo. 
[...] nas baixadas úmidas e pantanosas próximas às várzeas do Rio Tamanduateí e ao pé da colina central, constituíram-se os primeiros bairros operários. Por essas áreas, passavam as estradas de ferro para permitir o deslocamento dos produtos. Os baixos preços dos terrenos atraíram fábricas e outros empreendimentos industriais ao longo das décadas de 1880 e 1890. Os cortiços consistiam na única alternativa de moradia proletária por sua localização próxima do serviço, geralmente em áreas sujeitas a alagamentos, onde os preços dos aluguéis eram mais baixos (PEREIRA, 2010, p.135).

\section{As ruas como local de folguedo}

As ruas e outros espaços públicos tornaram-se os locais propícios para o encontro das crianças e jovens, que não tinham espaço para brincadeiras e jogos nas suas moradias. A diversão nas áreas livres sempre envolvia muitas pessoas e normalmente a consequência era "muita algazarra", que consequentemente incomodava os vizinhos. Por conta destas reclamações foi possível listar os bairros em que mais ocorriam essas brincadeiras, como o Brás, o Cambuci, a Sé e Santa Efigênia5. O bairro do Brás, da Sé e do Cambuci estavam nas proximidades com o rio Tamanduateí e, como pode ser visto no mapa abaixo, estavam no centro da cidade, muitas de suas ruas desembocavam ou cruzavam com o rio. No bairro de Santa Efigênia a diversão era praticada nas praças ou nos terrenos vazios.

Planta geral da cidade de São Paulo, 1905 (fragmento)

\footnotetext{
${ }^{5}$ Hoje em dia o bairro de Santa Efigênia faz parte do bairro da República. Rev. Caminhos da Educação: diálogos, culturas e diversidades, Teresina, v. 2, n. 1, p. 127-135 42 jan./abr. 2020
} 


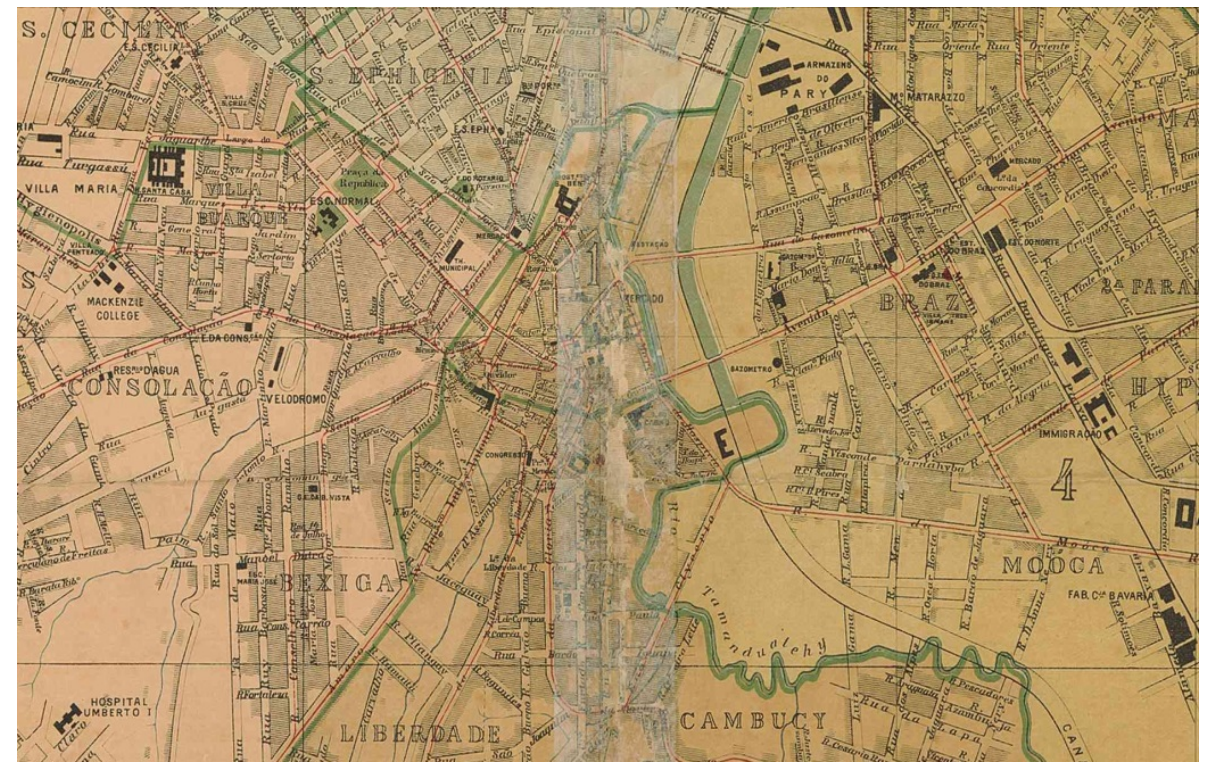

Fonte: SÃO PAULO. Secretaria de Estado de Economia e Planejamento. Instituto Geográfico e Cartográfico.

Os jovens utilizavam como ponto de encontro um terreno que existia nas proximidades entre a Igreja da Ordem Terceira do Carmo e do Mercado Municipal, as margens do rio Tamanduateí, conhecido como Várzea do Carmo ${ }^{6}$. Era um terreno público muito grande, com solo bem irregular, alguns arbustos pequenos e grama. Toda vez que chovia ficava com partes alagadas com a água da chuva e, com a água do rio que transbordava, outras partes tornavam-se pequenos lagos e, exatamente por esse motivo, não existia nenhum tipo de construção. Era o local ideal para todos os tipos de brincadeiras, com ou sem os alagamentos. Dois quilômetros adiante, o rio Tamanduateí desaguava no rio Tietê ${ }^{7}$, aumentando o volume das águas e os riscos para as brincadeiras.

As 8 horas da manhan de hontem, diversos menores, entre elles João de 10 annos de edade, filho de Francisco Menacchi, morador a rua Eduardo Chaves, n.11, brincavam em um batelão de arêa, em uma das margens do rio Tamanduateí, próximo ao lugar em que desemboca no Tieté.

Em dado momento, João, que se achava em uma das extremidades da embarcação, perdeu o equilíbrio, caindo na água. (...)

\footnotetext{
${ }^{6}$ A partir de 1967 passou a abrigar o Terminal de ônibus Dom Pedro II e o Parque Dom Pedro II.

${ }^{7}$ Os rios permanecem com a mesma denominação, apenas partes do trajeto do rio Tamanduateí foram modificadas por serem muito sinuosas.

136 Rev. Caminhos da Educação: diálogos, culturas e diversidades, Teresina, v. 2, n. 1, p. 127 -

142, jan./abr. 2020
} 
$\mathrm{O}$ cadaver foi encontrado às 3horas da tarde no rio Tieté. (SÃO PAULO, 30/11/1909, p.4)

Os jogos mais praticados neste local descampado eram o futebol e o campo de batalha nos dias em que não chovia, quando o terreno estava seco. O futebol era jogado por vários meninos que corriam atrás de uma pelota feita de panos enrolados, e normalmente discutiam entre si por várias razões diferentes - dificilmente uma disputa de futebol terminava pacífica. Esse era o motivo dos vizinhos reclamarem quando o jogo acontecia nas ruas como no Cambuci ou na Santa Efigênia e não na Várzea do Carmo.

As pessoas escreviam para o jornal pedindo para que a polícia tomasse providências "contra diversos menores que jogam foot-ball na rua" porque "perturbam a tranquilidade" de todos os moradores da vizinhança; além de quebrarem vidraças das janelas, claro porque precisavam de muito treino, esse era ainda um esporte novo que começava a ser difundido entre a elite e, as crianças e jovens de qualquer classe como brincadeira.

No campo do Osorio, como é conhecida a extensa várzea banhada pelo Tamanduatehy, no trecho compreendido da rua Glicerio á rua da Moóca, reúnem-se, á tarde, diversos grupos de menores que alli fazem training de foot-ball.

Como nas tardes anteriores, desde muito cedo, muitos menores passavam alli a tarde, entretidos em um match de foot-ball, que, ao contrário dos outros dias, foi triste. Um dos meninos que se divertiam com o foot-ball, logo no primeiro tempo, seguindo a bela arremessada num shot violento, desviou-se do campo e foi ter ao local em que a mesma caira, num pequeno matagal.

Esse menor, de 13 anos de edade apenas, Theodoro Leonardo, ao chegar se nesse matagal, foi mordido em uma das pernas por uma cobra, que dizem ser um urutú. (SÃO PAULO, 29/12/1908, p.3)

Claro, existiam outros problemas inesperados, além da reclamação dos vizinhos com a brincadeira, como encontrar uma cobra. Os meninos que jogavam futebol nas ruas no bairro de Santa Efigênia faziam a pelota com pedaços de panos, de jornal, de palha, não se tem conhecimento se chegaram a ter uma bola de outro material.

Os jovens e as crianças brincavam também de fazer balões e de nadar pelos rios. Utilizando-se dos estudos de Kishimoto (2016) os jogos podem ser entendidos como atividades mais estruturadas e organizadas, porque fazem uso de regras mais claras. Por Rev. Caminhos da Educação: diálogos, culturas e diversidades, Teresina, v. 2, n. 1, p. 127-137 42 jan./abr. 2020 
esse motivo o jogo de futebol e o campo de batalha podem ser classificados como jogos, apesar de existir a possibilidade de crianças participarem dessas atividades.

O Campo de Batalha foi um jogo bem popular entre esses meninos que se reuniam na Várzea do Carmo. Era um jogo coletivo, os meninos dividiam-se em dois grupos e lutavam entre si com pedras de todos os tamanhos, vencia o grupo que no final tivesse o maior número de participantes sem nenhum arranhão, ou que ninguém estivesse sangrando. $\mathrm{O}$ que na verdade parecia ser bem difícil. $\mathrm{O}$ jornal relatava que as batalhas eram frequentes na Várzea no Carmo "reúnem-se diariamente inúmeros menores, divididos em grupos, transformam aquelle logradouro em um campo de batalha”. E, aos finais de semana a quantidade de participantes aumentava, ocasionando em "renhidos combates a pedradas". Os meninos pequenos participavam deste jogo longe dos maiores, "afim de fazerem o combate as pedras e pelotas", muitos saiam machucados com pedradas e tijoladas.

Uma brincadeira muito comum que acontecia nas ruas era a manufatura de balões com tochas de fogo e sua posterior soltura nos céus da cidade. O problema era que, quando acabava o lume que mantinha aceso o balão, ele caia e quem o pegasse poderia tornava-se seu proprietário. Esse era o momento em que começavam as brigas e confusões entre os meninos que corriam para resgatar o balão que caia do céu, porque todos poderiam ser capazes de pegá-lo. Eram várias as reclamações da população contra a "algazarra da meninada nos arrabaldes" pela caça aos balões.

$\mathrm{Na}$ época actual, é frequente vêr-se nas ruas dos arrabaldes numerosos bandos de menores a seguir com os olhos os balões que vão pelo espaço, e a procurar, no meio de uma algazarra infernal, o local onde elles cairão.

Dois meninos, Santini Hippolito e Joaquim Cardoso procuravam ser os primeiros a agarrarl-o o almejado balão, por que, Cardoso rasgou-o com uma vara.

Indignado Santini abandonou o balão e avançando resolutamente para o adversário, agrediu-o a sôcos e a pontapés. Um soldado que passava, levou-os à presença do sub-delegado, que os mandou recolher ao xadrez. (SÃO PAULO, 23/5/1910, p.3)

Nesse caso, os garotos foram presos porque estavam brigando na rua por causa de um balão, tumultuando a pacífica vizinhança. Este era um motivo para levar os meninos para o xadrez, eles deveriam ter a sensatez dos adultos e resolver suas 
diferenças. Outras vezes, a questão dos balões e seu resgate, acarretavam consequências mais drásticas. Nos anos iniciais do século XX a cidade já contava com várias ruas com iluminação pública e os fios de alta tensão começavam a aparecer pelas ruas. Em uma das notícias um garoto acabou "fulminado" quando tentou retirar um balão "preso nos fios da Light". Esse era o nome da companhia de energia na época da cidade, a São Paulo Trainway, Light and Power Company, que começou a funcionar a partir de 1901 com a iluminação nas ruas e nos bondes elétricos.

A brincadeira, por fazer uso do brinquedo, acaba sendo vinculada mais aos pequenos. Esta tem algumas regras, limitando-se mais ao lúdico, a criança pode mudar essas regras, entrar e sair da brincadeira que não vai alterá-la. Kishimoto (2016) ainda acrescenta que impera a liberdade da criança. Normalmente existe um brinquedo em uma brincadeira estabelecida e também existe brincadeira sem estruturas, dependem somente da imaginação das crianças.

Os sujeitos desta pesquisa estavam as voltas com brincadeiras e brinquedos, na maior parte das vezes, sem estruturas. Eles se divertiam em grupos jogando pequenas pedras nos trilhos dos bondes, apenas para vê-las se quebrarem quando o bonde passava. Certamente, algumas vezes eles erravam o local do trilho e acertavam as pessoas dentro do transporte, o que causava certa confusão. As notícias do periódico lido faz menção a este fato. Essas crianças também se divertiam tomando banho no rio Tamanduateí sem o uso de roupas, o que originava alguns transtornos e tumultos com a ordem pública. Passeavam de bote pelo rio "devido as torrencias chuvas que caíram nesses últimos dias na capital, ha grande inundação [...] durante a tarde, muitas creanças se divertem, passeando em botes, canoas e outras pequenas embarcações”.

Os meninos jogavam foot-ball nas paredes laterais da Igreja da Ordem Terceira do Carmo, fazendo muito barulho e atrapalhando as orações dos fiéis. Local próximo a várzea que estavam acostumados a reunirem-se para jogarem e brincarem. Todas essas ações eram diversão para os que estavam acostumados às ruas da cidade e consideravam-nas como parte de suas casas.

\section{Considerações Finais}

As crianças e jovens que viveram na cidade de São Paulo puderam se divertir a sua maneira. Claro que vivenciaram muitos conflitos simultâneos ao entretenimento. 
Parecia ser sempre muito divertido nadar no rio Tamanduateí sem roupa, desde que nenhum morador da região avistasse os meninos e avisa-se o guarda rondante. $\mathrm{O}$ problema estava na idade dos meninos, os maiores eram considerados "marmanjos" quando tiravam a roupa ficavam indecentes, só os muito pequenos podiam banhar-se nus. Porém, tem-se de pensar neste caso em algumas hipóteses, mesmo numa época em que existiam trajes para banho de mar, essa população não tinha acesso a ela. Para entrar na água do rio ou usavam a própria roupa ou tiravam tudo o que era possível para não molhar. O problema estava na idade avançada dos rapazes que tomavam banho no rio, porque as lavadeiras usavam o mesmo rio, com poucos metros de distância do local aonde eram avistados os banhistas nus. Outra hipótese é a de que algum dos banhistas fosse para o meio do rio e, com a correnteza não conseguisse voltar precisando chamar alguém para ajudar.

O jogo que acontecia na Várzea do Carmo, o Campo de Batalha, era realmente uma guerra de pedras entre duas equipes, e eles terminavam a disputa sempre machucados, com pedradas. Na verdade, esse era o objetivo principal do jogo - acertar uma pedrada no inimigo. $\mathrm{O}$ guarda rondante foi chamado algumas vezes pelas brigas e por causa de meninos muito machucados por pedradas durante esse jogo. As pedras eram colhidas no terreno em que a competição acontecia. A Várzea do Carmo era um bom local por ter pedras, morros para o esconderijo, grama, reunia todos os quesitos para o jogo.

E, o futebol, que estava sendo difundido como um jogo da elite, entre os trabalhadores das fábricas inglesas na cidade, era jogado pelos meninos nas ruas e na várzea do rio Tamanduateí desde 1902. As notícias dos periódicos analisados já citam os "menores" jogando foot-ball com bola improvisada desde o início do século XX e, certamente interferindo na ordenação da cidade, nas praças públicas e ruas.

Entretanto, o mais preocupante nessa pesquisa é aonde estavam as meninas?. Elas não foram citadas, será que não estavam nos treinos de futebol, ou nas equipes do jogo campo de batalha, ou entre aqueles que jogavam pedras nos trilhos dos bondes, correndo atrás dos balões?. Somente os meninos foram citados em todas essas notícias, todos os nomes de "menores vadios" anotados pelos guardas e levados para o "xadrez" eram nomes masculinos.

Foram identificados anúncios solicitando meninas para trabalharem em serviços domésticos, seria esse o motivo para elas não estarem entre os meninos? Estariam 
trabalhando nas fábricas, nas casas de família exercendo os serviços domésticos? Poderiam ser em menor número e por isso nem chegaram a ser citadas?. O que teria acontecido?. A pesquisa continua em busca de novos indícios para essas perguntas

\section{Referências}

BIONDI, Luigi. Imigração italiana e movimento operário em São Paulo: um balanço historiográfico. In: CARNEIRO, Maria Luiza Tucci; CROCI, Federico \& FRANZINA, Emilio (Org.s) História do trabalho e História da imigração: trabalhadores italianos e sindicatos no Brasil (séculos XIX e XX). São Paulo: Editora da Universidade de São Paulo: Fundação de Amparo à Pesquisa do Estado de São Paulo, 2010, p. 23-48. CERTEAU, Michel de. A escrita da História. 3. ed. Tradução Maria de Lourdes Menezes. Rio de Janeiro: Forense Universitária, 2011.

CHARTIER, Roger. Escutar os mortos com os olhos. Tradução Jean Briant. Estudos Avançados. São Paulo, v. 24, n. 69, p. 07-30, 2010.

COHEN, Ilka Stern. Diversificação e Segmentação dos Impressos. In: MARTINS, Ana Luiza; LUCA, Tania Regina de. História da Imprensa no Brasil. São Paulo: Contexto, 2013. p. 103-130.

CRUZ, Heloisa de Faria. São Paulo em papel e tinta: periodismo e vida urbana 18901915. São Paulo: Arquivo Público do Estado de São Paulo, 2013.

ELEUTÉRIO, Maria de Lourdes. Imprensa a serviço do progresso. In: MARTINS, Ana Luiza e LUCA, Tânia Regina de (org.). História da Imprensa no Brasil. São Paulo: Contexto, 2013.

KISHIMOTO, Tizuko Morchida. O jogo e a educação infantil. Ed. ver. São Paulo: Cengage Learning, 2016.

LUCA, Tânia Regina de. História dos, nos e por meio dos periódicos. In: PINSKY, Carla Bassanezi et al. Fontes Históricas. 2. ed. São Paulo: Contexto, 2005, p. 111-154. MATOS, Maria Izilda Santos de. Cotidiano e cultura: história, cidade e trabalho. Bauru/SP: Editora da Universidade Sagrado Coração, 2002

MATHEUS, Leticia Cantarela. Um "spam telegráfico": investigações sobre novas formas de circulação noticiosa no final do século XIX no Brasil. In: MATHEUS, Leticia Cantarela (org.). História da Comunicação: experiências e perspectivas. Rio de Janeiro: Mauad X, 2014. p. 113-134. 
AUTOR . A educação e os imigrantes italianos: da escola de primeiras letras ao grupo escolar. 2. ed. São Paulo: Iglu, 2010.

. (org.) Bambini Brasiliani: a infância das crianças italianas e ítalo-brasileiras. Jundiaí/SP: Paco Editorial, 2013.

MOURA, Esmeralda Blanco Bolsonaro de. Crianças operárias na recém industrializada

São Paulo. In: PRIORE, Mary del (org.) História das crianças no Brasil. 2. ed. São Paulo: Contexto, 2000, p. 259-288.

PEREIRA, Robson Mendonça. Washington Luís na administração de São Paulo (19141919). São Paulo: Editora da Universidade Estadual Paulista, 2010.

AUTOR. O convívio concomitante e frugal das escolas elementares públicas e privadas paulistanas. Educar em Revista. Curitiba, v. 58, p. 183-198, out./dez. 2015.

- Indícios corriqueiros da vida de jovens e crianças na cidade de São Paulo (1870-1912). História Unicap. Recife, v. 5, n. 9, p. 119-133, jan./jun. 2018.

SÃO PAULO. Secretaria de Estado de Economia e Planejamento. Instituto Geográfico e Cartográfico. Planta geral da cidade de São Paulo, 1905. O Estado de S. Paulo, 1906, 1908, 1909,1910. 